\title{
ANALISIS POSTUR KERJA \\ DENGAN METODE OWAS (OVAKO WORKING POSTURE ANALYSIS SYSTEM) DAN QEC (QUICK EXPOSURE CHECKLIST) UNTUK MENGURANGI TERJADINYA KELELAHAN MUSCULOSKELETAL DISORDERS DI PT. TRUVA PASIFIK
}

\author{
Sofian Bastuti' ${ }^{1)}$, Marjuki Zulziar ${ }^{1)}$, Edih Suaedih ${ }^{2)}$ \\ ${ }^{1)}$ Dosen Teknik Industri, Universitas Pamulang, ${ }^{2)}$ Mahasiswa Teknik Industri, Universitas Pamulang \\ dosen00954@unpam.ac.id
}

\begin{abstract}
ABSTRAK
Telah dilakukan penelitian analisis postur kerja di PT. Truva Pasifik dengan inti masalah kelelahan musculoskeletal disorders dengan metode OWAS dan metode QEC sebagai alat deteksi kelelahan tersebut. Hasil analisis $\boldsymbol{O W A S}$ menunjukkan 4 postur kerja yang memerlukan perbaikan yaitu kategori skor 4 (perbaikan perlu dilakukan sekarang juga) pada 1 elemen kegiatan postur kerja. Selanjutnya kategori skor 3 (perbaikan perlu dilakukan segera mungkin) pada 3 elemen kegiatan postur kerja. Sedangkan hasil metode QEC menunjukkan nilai action level 70,5\% terdapat pada 1 elemen kegiatan postur kerja dengan tingkat risiko 4 (investigasi lebih lanjut dan dilakukan penanganan secepatnya), nilai action level 65,9\%, 63,6\%, dan 63,1\% terdapat pada 3 elemen kegiatan postur kerja dengan tingkat risiko 3 (investigasi lebih lanjut dan dilakukan penanganan dalam waktu dekat). Usulan perbaikan pada postur kerja adalah dengan merubah gerakan postur kerja dan menambahkan alat bantu seperti trolley dan pijakan kaki untuk mengurangi tingkat risiko cidera musculoskeletal bagi pekerja.
\end{abstract}

Kata kunci: MSDs, Postur Kerja, OWAS, QEC

\section{PENDAHULUAN}

\section{A. Latar Belakang Masalah}

Postur kerja operator dalam setiap melakukan pekerjaannya mempunyai gerakan postur tubuh yang berbeda-beda, gerakan tersebut dapat dipengaruhi oleh kondisi dari stasiun kerja tempat operator dalam melakukan aktivitasnya. Setiap operator dalam lingkungan kerjanya selalu menginginkan pekerjaan yang dapat dikerjakan dengan tenaga yang seminimal mungkin, tetapi dapat memberikan hasil yang maksimal sesuai harapan yang diinginkan.

PT. Truva Pasifik merupakan perusahaan yang bergerak dalam industri manufaktur pembuatan arang briket kelapa. Pembuatan arang briket yang diproduksi di perusahaan ini jenis sisha, pada proses produksi di perusahaan PT. Truva Pasifik masih ada yang bersifat manual handling dalam melakukan pekerjaannya baik dalam melakukan proses mengangkat, membawa, mendorong, proses penyortiran dan proses pengepakan barang yang ada di perusahaan sehingga masih memerlukan banyak tenaga manusia yang ada didalamnya. Pekerjaan manual handling pada operator di PT. Truva Pasifik dengan postur kerja yang tidak alamiah saat melakukan pekerjaannya dapat cepat mengalami keluhan musculoskeletal disorders yang dirasakan oleh operator. Kondisi sikap kerja di PT. Truva Pasifik pada departemen produksi sering mengalami keluhan terhadap postur kerjanya karena masih banyak postur kerja operator departemen produksi yang tidak alami. Postur kerja operator tersebut pada bagian kerja yang terlalu lama berdiri, jongkok, membungkuk, mengangkat dengan frekuensi tinggi dalam kurun waktu lama yang dapat menyebabkan ketidaknyamanan dan nyeri pada salah satu anggota tubuh para pekerja. Berdasarkan hasil survey pendahuluan dan wawancara awal yang dilakukan terhadap operator departemen produksi terdapat keluhan yang sering dirasakan sakit operator akibat postur kerja 
yang tidak alami, berupa sakit dibagian anggota tubuh punggung, bagian bahu kanan, bagian tangan kanan, bagian leher bagian bawah, bagian betis kanan, dan bagian pinggang. Salah satu upaya untuk mengatasi hal ini adalah dengan menganti metode yang telah dilakukan menjadi metode yang ergonomis. Oleh karena itu, perlu adanya perbaikan untuk mengurangi keluhan yang dialami operator di departemen produksi tersebut, agar operator merasa efektif, nyaman, dan aman dalam bekerja. Saat ini operator yang bekerja di departemen produksi PT. Truva Pasifik berjumlah 184 pekerja. Operator yang dipilih untuk mengisi kuesioner nordis body map sebanyak 126 responden. Berikut adalah keluhan otot/sendi (MSDs) yang dirasakan oleh 126 operator departemen produksi di PT. Truva Pasifik berdasarkan kuesioner nordic body map dapat dilihat pada Tabel 1.1.

\section{Tabel 1.1 Kuesioner Nordic Body Map} Departemen Produksi

\begin{tabular}{|c|l|c|c|c|c|}
\hline \multirow{2}{*}{ No. } & Jenis Keluhan/Lokasi Keluhan & \multicolumn{4}{|c|}{ Keluhan Musculoskeletal Disorders } \\
\cline { 3 - 6 } & & $\begin{array}{c}\text { n } \\
\text { (responden } \\
\text { pekerja) }\end{array}$ & $\begin{array}{c}\text { Sakit } \\
\text { \% }\end{array}$ & $\begin{array}{c}\text { n } \\
\text { (responden } \\
\text { pekerja) }\end{array}$ & $\begin{array}{c}\text { Tidak } \\
\text { Sakit } \\
\text { \% }\end{array}$ \\
\hline 0 & Sakit/kaku pada leher bagian atas & 50 & 39.7 & 76 & 60.3 \\
\hline 1 & Sakit/kaku pada leher bagian bawah & $\mathbf{9 9}$ & $\mathbf{7 8 . 6}$ & 27 & 21.4 \\
\hline 2 & Sakit pada bahu kiri & 48 & 38.1 & 78 & 61.9 \\
\hline 3 & Sakit pada bahu kanan & $\mathbf{1 1 0}$ & 87.3 & 16 & 12.7 \\
\hline 4 & Sakit pada lengan atas kiri & 20 & 15.9 & 106 & 84.1 \\
\hline 5 & Sakit pada punggung & $\mathbf{1 1 4}$ & $\mathbf{9 0 . 5}$ & 12 & 9.5 \\
\hline 6 & Sakit pada lengan atas kanan & 19 & 15.1 & 107 & 84.9 \\
\hline 7 & Sakit pada pinggang & $\mathbf{9 0}$ & 71.4 & 36 & 28.6 \\
\hline 8 & Sakit pada bokong & 43 & 34.1 & 83 & 65.9 \\
\hline 9 & Sakit pada pantat & 2 & 1.6 & 124 & 98.4 \\
\hline 10 & Sakit pada siku kiri & 0 & 0 & 126 & 100 \\
\hline 11 & Sakit pada siku kanan & 0 & 0 & 126 & 100 \\
\hline 12 & Sakit pada lengan bawah kiri & 0 & 0 & 126 & 100 \\
\hline 13 & Sakit pada lengan bawah kanan & 0 & 0 & 126 & 100 \\
\hline 14 & Sakit pada pergelangan tangan kiri & 37 & 29.4 & 89 & 70.6 \\
\hline 15 & Sakit pada pergelangan tangan kanan & 34 & 27 & 92 & 73 \\
\hline 16 & Sakit pada tangan kiri & 34 & 27 & 92 & 73 \\
\hline 17 & Sakit pada tangan kanan & $\mathbf{1 0 3}$ & $\mathbf{8 1 . 7}$ & 23 & 18.3 \\
\hline 18 & Sakit pada paha kiri & 37 & 29.4 & 89 & 70.6 \\
\hline 19 & Sakit pada paha kanan & 11 & 8.7 & 115 & 91.3 \\
\hline 20 & Sakit pada lutut kiri & 28 & 22.2 & 98 & 77.8 \\
\hline 21 & Sakit pada lutut kanan & 33 & 26.2 & 93 & 73.8 \\
\hline 22 & Sakit pada betis kiri & 49 & 38.9 & 77 & 61.1 \\
\hline 23 & Sakit pada betis kanan & $\mathbf{9 9}$ & $\mathbf{7 8 . 6}$ & 27 & 21.4 \\
\hline 24 & Sakit pada pergelangan kaki kiri & 25 & 19.8 & 101 & 80.2 \\
\hline 25 & Sakit pada pergelangan kaki kanan & 26 & 20.6 & 100 & 79.4 \\
\hline 26 & Sakit pada kaki kiri & 39 & 31 & 87 & 69 \\
\hline 27 & Sakit pada kaki kanan & 13 & 10.3 & 113 & 89.7 \\
\hline
\end{tabular}

(Sumber: Pengolahan dari Berbagai Sumber)

Dalam jurnalnya, Palit dan Aysia (2015) melaporkan bahwa terdapat $75 \%$ pekerja bagian packing yang diwawancara mengalami keluhan pada kaki dan bahu, pada hasil penelitian dengan Metode penilaian OWAS menunjukkan bagian tubuh dari postur kerja yang berisiko stres postur karena pekerjaan pengemasan kaki dan punggung, yang terkait dengan keluhan pekerja yang diperoleh dari wawancara menggunakan nordic body map. Dari hasil datadata yang terus menunjukkan gangguan terhadap musculoskeletal disorders diberbagai jenis industri manufaktur diberbagai dunia dan terutama negara Indonesia terlihat bahwa masalah ergonomi yang paling penting dihadapi di tempat kerja dan perlu mendapatkan perhatian yang sangat serius dari pihak manajemen perusahaan untuk dapat mengurangi terjadinya keluhan musculoskeletal disorders pada pekerja. Oleh karena itu, identifikasi resiko ergonomi pada pekerjaan di departemen produksi PT. Truva Pasifik sangat penting sebagai langkah awal pencegahan, dengan memberikan risiko penilaian postur kerja menggunakan metode OWAS (Ovako Working Posture Analysis System) dan QEC (Quick Exposure Cheklist) yang akan dilakukan pada operator, merupakan sebuah metode yang dikembangkan dalam bidang ergonomi dan dapat digunakan secara cepat untuk menilai posisi kerja atau sikap kerja pada masingmasing postur. Tujuan dari penelitian ini adalah untuk mengetahui postur kerja pada operator departemen produksi di PT. Truva Pasifik dan untuk mengetahui hasil aplikasi metode OWAS (Ovako Working Posture Analyis System) dan QEC (Quick Exposure Checklist).

\section{DASAR TEORI}

Secara etimologis, ergonomi berasal dari dua kata Yunani, ergon berarti kerja dan nomos berarti hukum alam. Ergonomi adalah cabang ilmu yang secara sistematis menggunakan informasi tentang sifat, keterampilan, dan keterbatasan manusia untuk merancang sistem kerja sehingga orang dapat hidup dan bekerja dalam sistem dengan benar, yaitu, mencapai tujuan yang diinginkan melalui karya orang. cara yang efektif, aman dan nyaman (Sutalaksana, 1979).

Menurut Tarwaka (2015:315), metode OWAS merupakan sebuah metode yang sederhana dan dapat digunakan untuk menganalisa suatu pembebanan pada postur tubuh. Metode ini mulai berkembang pada awal tahun tujuh puluhan di perusahaan Ovako Oy Finlandia (sekarang bernama Fundia Wire). Klasifikasi postur kerja dari metode OWAS (Ovako Working Posture Analysis System) adalah pada pergerakan tubuh bagian belakang (back), lengan (arms), dan kaki (legs), dan beban (loads). Setiap postur tubuh tersebut 
terdiri dari 4 postur bagian belakang, 3 postur lengan, dan 7 postur kaki. Berat beban yang dikerjakan juga dilakukan penilaian mengandung skala 3 point (nilai). Hasil dari analisa sikap kerja OWAS (Ovako Working Posture Analysis System) terdiri dari empat level skala sikap kerja yang berbahaya bagi para pekerja dapat dilihat pada Tabel 2.1.

Tabel 2.1 Empat Kategori Tindakan OWAS

\begin{tabular}{|c|l|}
\hline $\begin{array}{c}\text { Kategori } \\
\text { Tindakan }\end{array}$ & \multicolumn{1}{c|}{ Tindakan } \\
\hline 1 & Aman \\
\hline 2 & $\begin{array}{l}\text { Diperlukan beberapa waktu } \\
\text { ke depan }\end{array}$ \\
\hline 3 & Tindakan dalam waktu dekat \\
\hline 4 & Tindakan sekarang juga \\
\hline
\end{tabular}

(Sumber: Karhu et al, 1981)

Quick Exposure Checklist (QEC) merupakan suatu metode ergonomi untuk melakukan penilaian postur kerja terhadap risiko kerja yang berhubungan dengan gangguan otot di tempat kerja. Quick Exposure Checklist (QEC) juga dikembangkan untuk memungkinkan praktisi kesehatan dan keselamatan untuk melakukan penilaian paparan pekerjaan untuk faktor risiko musculoskeletal ( $\mathrm{Li}$ and Buckle dalam Madschen, 2012). Quick Exposure Checklist (QEC) dapat dengan cepat mengidentifikasi tingkat keluhan punggung, bahu / lengan, pergelangan tangan dan leher.. Action level dalam penelitian ini seperti Tabel 2.2.

Tabel 2.2 Action Level QEC

\begin{tabular}{|c|l|}
\hline $\begin{array}{c}\text { Total } \\
\text { Exposure } \\
\text { Level }\end{array}$ & \multicolumn{1}{|c|}{ Action (Penanganan) } \\
\hline$<40 \%$ & Aman \\
\hline $40-49 \%$ & Perlu penelitian lebih lanjut \\
\hline $50-69 \%$ & $\begin{array}{l}\text { Perlu penelitian lebih lanjut } \\
\text { dan dilakukan perubahan }\end{array}$ \\
\hline$\geq 70 \%$ & $\begin{array}{l}\text { Dilakukan penelitian dan } \\
\text { perubahan secepatnya }\end{array}$ \\
\hline
\end{tabular}

(Sumber: Jurnal Ilman et al, 2013)

\section{METODE DAN TEKNIK PENGUKURAN}

Penelitian dilakukan di PT. Truva Pasifik merupakan perusahaan yang bergerak dibidang industri pembuatan arang briket yang berada di Kampung Setu, Desa Panongan, Kabupaten
Tangerang, Banten. Penelitian ini difokuskan pada masalah analisa postur kerja pada departemen produksi. Penelitian dilaksanakan selama dua bulan yaitu dari bulan Oktober 2018 sampai dengan bulan November 2018.

Jenis penelitian yang dilakukan menggunakan penelitian metode pendekatan deskriptif. Metode pendekatan deskriptif pada penelitian ini digunakan untuk menjawab permasalahan postur kerja atau cara kerja dan mengkategorikan aktivitas pekerjaan yang dilakukan operator secara terperinci pada departemen produksi arang briket di PT. Tuva Pasifik. Ukuran sampel untuk penyebaran kuesioner nordic body map dihitung dengan menggunakan rumus slovin. Jumlah populasi pekerja pada departemen produksi di PT. Truva pasifik yaitu sebanyak 184 pekerja dengan tingkat ketelitian 5\%. Rumus slovin:

Di mana:

$$
n=\frac{\mathrm{N}}{\mathrm{N} \cdot e^{2}+1}
$$

$\mathrm{n}=$ jumlah sampel

$\mathrm{N}=$ jumlah populasi

$e^{2}=$ batas ketelitian yang diinginkan

Hasil perhitungan:

$$
\begin{aligned}
& n=\frac{184}{184 \cdot(0,05)^{2}+1} \\
& n=\frac{184}{184 \cdot 0,0025+1} \\
& n=\frac{184}{1,46}
\end{aligned}
$$$$
n=126 \text { pekerja. }
$$

Berdasarkan perhitungan sampel di atas, total sampel yang digunakan dalam penelitian untuk penyebaran kuesioner nordic body map sebanyak 126 pekerja untuk mengetahui gambaran keluhan musculoskeletal disorders pada pekerja di departemen produksi, sampel tersebut sudah mewakili populasi. Setelah dilakukan perhitungan gambaran keluhan musculoskeletal disorders dengan kuesioner nordic boy map maka dilakukan pemetaan pada postur kerja yang ada di departemen produksi untuk dilakukan penelitian oleh peneliti. Pemetaan tersebut peneliti mengambil 19 sampel postur kerja atau elemen kegiatan dari 8 stasiun bagian kerja dapat dilakukan melalui proses mengambil gambar dan video pekerja saat bekerja di elemen kegiatan dan stasiun kerja masing-masing yang ada pada departemen produksi.

\section{HASIL DAN PEMBAHASAN}


Penelitian mengenai keluhan MSDs dilakukan dengan pengisian nordic body map yang diklasifikasian pada 28 bagian tubuh kepada seluruh pekerja (operator) departemen produksi di PT. Truva Pasifik, Panongan, Tangerang, Banten. Keluhan MSDs ini merupakan rasa sakit (salah satu atau gabungan dari rasa pegal, nyeri, kesemutan, panas, kejang, kaku, ataupun bengkak) yang dirasakan oleh pekerja pada bagian postur tubuh setelah melakukan pekerjaannya. Dari jumlah keluhan yang dirasakan oleh 126 responden (sampel) dapat dilihat pada tabel distribusi keluhan MSDs pada lokasi tubuh pekerja (operator) departemen produksi pembuatan arang briket pada Tabel 4.1.

Tabel 4.1 Distribusi Keluhan MSDs Berdasarkan Lokasi Keluhan Pada Pekerja Pembuatan Arang Briket

\begin{tabular}{|c|l|c|c|c|c|}
\hline \multirow{2}{*}{ No. } & Jenis Keluhan/Lokasi Keluhan & \multicolumn{4}{|c|}{ Keluhan Musculoskeletal Disorders } \\
\cline { 3 - 7 } & & $\begin{array}{c}\mathbf{n} \\
\text { (responden } \\
\text { pekerja) }\end{array}$ & $\begin{array}{c}\text { Sakit } \\
\mathbf{\%}\end{array}$ & $\begin{array}{c}\mathbf{n} \\
\text { (responden } \\
\text { pekerja) }\end{array}$ & $\begin{array}{c}\text { Tidak } \\
\text { Sakit } \\
\mathbf{\%}\end{array}$ \\
\hline 0 & Sakit/kaku pada leher bagian atas & 50 & 39.7 & 76 & 60.3 \\
\hline 1 & Sakit/kaku pada leher bagian bawah & $\mathbf{9 9}$ & 78.6 & 27 & 21.4 \\
\hline 2 & Sakit pada bahu kiri & 48 & 38.1 & 78 & 61.9 \\
\hline 3 & Sakit pada bahu kanan & $\mathbf{1 1 0}$ & $\mathbf{8 7 . 3}$ & 16 & 12.7 \\
\hline 4 & Sakit pada lengan atas kiri & 20 & 15.9 & 106 & 84.1 \\
\hline 5 & Sakit pada punggung & $\mathbf{1 1 4}$ & $\mathbf{9 0 . 5}$ & 12 & 9.5 \\
\hline 6 & Sakit pada lengan atas kanan & 19 & 15.1 & 107 & 84.9 \\
\hline 7 & Sakit pada pinggang & $\mathbf{9 0}$ & 71.4 & 36 & 28.6 \\
\hline 8 & Sakit pada bokong & 43 & 34.1 & 83 & 65.9 \\
\hline 9 & Sakit pada pantat & 2 & 1.6 & 124 & 98.4 \\
\hline 10 & Sakit pada siku kiri & 0 & 0 & 126 & 100 \\
\hline 11 & Sakit pada siku kanan & 0 & 0 & 126 & 100 \\
\hline 12 & Sakit pada lengan bawah kiri & 0 & 0 & 126 & 100 \\
\hline 13 & Sakit pada lengan bawah kanan & 0 & 0 & 126 & 100 \\
\hline 14 & Sakit pada pergelangan tangan kiri & 37 & 29.4 & 89 & 70.6 \\
\hline 15 & Sakit pada pergelangan tangan kanan & 34 & 27 & 92 & 73 \\
\hline 16 & Sakit pada tangan kiri & 34 & 27 & 92 & 73 \\
\hline 17 & Sakit pada tangan kanan & $\mathbf{1 0 3}$ & $\mathbf{8 1 . 7}$ & 23 & 18.3 \\
\hline 18 & Sakit pada paha kiri & 37 & 29.4 & 89 & 70.6 \\
\hline 19 & Sakit pada paha kanan & 11 & 8.7 & 115 & 91.3 \\
\hline 20 & Sakit pada lutut kiri & 28 & 22.2 & 98 & 77.8 \\
\hline 21 & Sakit pada lutut kanan & 33 & 26.2 & 93 & 73.8 \\
\hline 22 & Sakit pada betis kiri & 49 & 38.9 & 77 & 61.1 \\
\hline 23 & Sakit pada betis kanan & $\mathbf{9 9}$ & 78.6 & 27 & 21.4 \\
\hline 24 & Sakit pada pergelangan kaki kiri & 25 & 19.8 & 101 & 80.2 \\
\hline 25 & Sakit pada pergelangan kaki kanan & 26 & 20.6 & 100 & 79.4 \\
\hline 26 & Sakit pada kaki kiri & 39 & 31 & 87 & 69 \\
\hline 27 & Sakit pada kaki kanan & 13 & 10.3 & 113 & 89.7 \\
\hline & & & & & \\
\hline
\end{tabular}

(Sumber: Pengolahan dari Berbagai Sumber)

Setelah mengetahui gambaran postur kerja operator di departemen produksi maka dilakukan pemetaan terhadap 19 postur kerja yang berpotensi menimbulkan keluhan tingkat risiko ergonomi yang dapat menyebabkan bahaya pada sistem musculoskeletal disorders (MSDs) pada postur tubuh operator, postur kerja tersebut terbagi dalam 8 bagian kerja meliputi stasiun kerja rotary, stasiun kerja diskmill, stasiun kerja mixer, stasiun kerja molding, stasiun kerja cutting, stasiun kerja susun, stasiun kerja oven (pengeringan), dan stasiun kerja packing. Berikut ini adalah penjelasan setiap bagian kerja dan postur kerja elemen kegiatan yang ada di departemen produksi dapat dilihat pada Tabel 4.2.

Tabel 4.2 Postur Kerja dan Elemen Kegiatan

\begin{tabular}{|c|c|c|c|}
\hline No & Stasiun Kerja & $\begin{array}{c}\text { Nomor } \\
\text { Postur } \\
\text { Kerja }\end{array}$ & Elemen Kegiatan \\
\hline \multirow{4}{*}{1} & \multirow{4}{*}{ Bahan Baku Rotary } & 1 & Menjangkau (mengambil) karung \\
\hline & & 2 & Mengangkat karung \\
\hline & & 3 & Menyusun karung \\
\hline & & 4 & Menyortir arang tempurung kelapa \\
\hline 2 & Bahan Baku Diskmill & 5 & Proses quality control bubuk arang \\
\hline \multirow{4}{*}{3} & \multirow{4}{*}{ Produksi Mixer } & 6 & Proses menyekrup bubuk arang \\
\hline & & 7 & Proses mengambil ember \\
\hline & & 8 & Proses mengangkat ember \\
\hline & & 9 & Proses menuangkan bubuk arang \\
\hline 4 & Produksi Molding & 10 & Proses molding (pencetakan) \\
\hline 5 & Produksi Cutting & 11 & Proses pemotongan bahan cetakan \\
\hline \multirow{2}{*}{6} & \multirow{2}{*}{ Produksi Susun } & 12 & Proses mengambil hasil Cetakan \\
\hline & & 13 & Proses penyusunan cetakan briket arang \\
\hline \multirow{3}{*}{7} & \multirow{3}{*}{ Oven (Pengeringan) } & 14 & Proses mengambil kayu \\
\hline & & 15 & Proses membawa Kayu \\
\hline & & 16 & Proses memasukkan Kayu \\
\hline \multirow{3}{*}{8} & \multirow{3}{*}{$\begin{array}{l}\text { Packing } \\
\text { (Pengepakan) }\end{array}$} & 17 & Packing plastik \\
\hline & & 18 & Packing box karton \\
\hline & & 19 & Packing tali \\
\hline
\end{tabular}

(Sumber: Pengolahan dari Berbagai Sumber)

\section{A. Penilaian Postur Kerja Dengan Metode OWAS (Ovako Working Posture Analysis System) Pada Departemen Produksi}

Analisis OWAS pada postur tubuh stasiun kerja bagian rotary, pada tahapan menjangkau/mengambil karung aktivitasnya seperti pada Gambar 4.2.

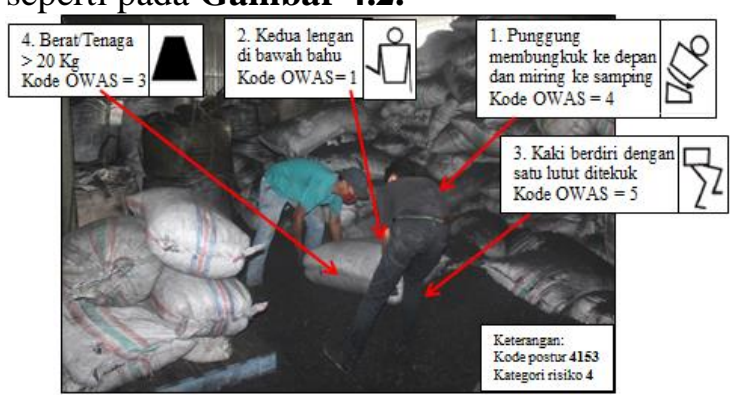

(Sumber: PT. Truva Pasifik, 2018)

Gambar 4.2 Tahapan Mengambil Karung

Tahapan menjangkau karung yang akan di susun ke palet, pada tahapan ini proses tahapan pertama yang dilakukan pekerja/operator setiap harinya dibagian rotary menyiapkan bahan baku ke palet untuk dibawa ke area penyortiran yang ada di dalam mesin rotary. Pada tahap ini postur tubuh operator membungkuk ke depan dan miring ke samping, posisi tangan memegang karung dan kepala menunduk. Berat karung yang berisi arang batok tempurung kelapa yang diangkat operator $>20 \mathrm{~kg}$. Postur tubuh pekerja pada Gambar 4.2 dapat 
dilakukan penilaian terhadap postur kerjanya dapat dilihat pada Tabel 4.3.

Tabel 4.3 Penilaian OWAS Tahapan Mengambil Karung

\begin{tabular}{|l|c|l|}
\hline \multicolumn{1}{|c|}{ Bagian Tubuh } & $\begin{array}{c}\text { Kode } \\
\text { OWAS }\end{array}$ & \multicolumn{1}{|c|}{ Deskripsi Postur } \\
\hline Punggung (Back) & 4 & $\begin{array}{l}\text { Bungkuk ke depan dan miring } \\
\text { ke samping }\end{array}$ \\
\hline Lengan (Arms) & 1 & Kedua lengan di bawah bahu \\
\hline Kaki (Legs) & 5 & $\begin{array}{l}\text { Berdiri dengan satu lutut } \\
\text { ditekuk }\end{array}$ \\
\hline Berat/Tenaga (Load) & 3 & $>20 \mathrm{Kg}$ \\
\hline
\end{tabular}

(Sumber: Pengolahan dari Berbagai Sumber)

Pekerjaan yang dilakukan operator tahapan mengambil karung pada Gambar 4.2 mendapatkan action code dan pada Tabel 4.4.

Tabel 4.4 Action Code OWAS Tahapan Mengambil Karung

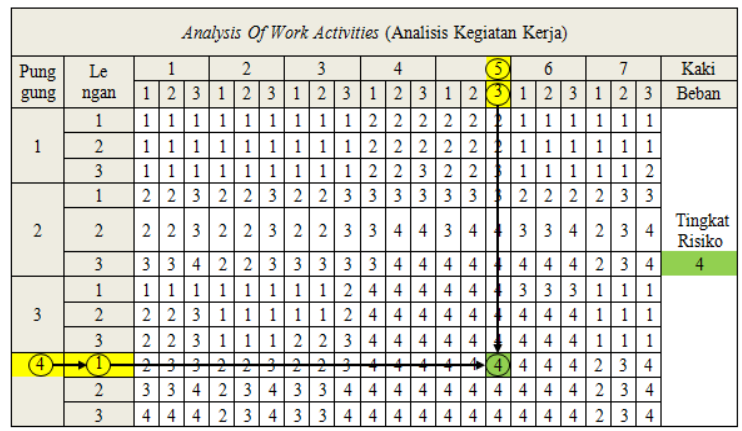

(Sumber: Pengolahan dari Berbagai Sumber)

Dari tabel analisis perhitungan OWAS pada Gambar 4.2 didapat bahwa kode OWAS yaitu: 4-1-5-3 dan nilai action code $=4$ yaitu pada sikap ini postur kerja berbahaya pada sistem musculoskeletal perlu tindakan perbaikan sekarang juga terhadap postur kerja ini, postur kerja ini dapat mengakibatkan risiko yang sangat jelas terhadap sistem musculoskeletal disorders pekerja.

Rekapitulasi hasil nilai akhir perhitungan postur kerja untuk ke 19 elemen kegiatan postur kerja pada 8 bagian stasiun kerja berdasarkan metode OWAS pada departemen produksi di PT. Truva Pasifik seperti Tabel 4.5.

Tabel 4.5 Nilai Akhir Postur Kerja OWAS

\begin{tabular}{|c|c|c|c|}
\hline $\begin{array}{l}\text { Nomor } \\
\text { Postur } \\
\text { Kerja } \\
\end{array}$ & Elemen Kegiatan & \begin{tabular}{|l|} 
Nilai \\
Akhir \\
Owas \\
\end{tabular} & Tindakan \\
\hline 1 & Mengambil Karung & 4 & Tindakan sekarang juga \\
\hline 2 & Mengangkat Karung & 3 & Tindakan dalam waktu dekat \\
\hline 3 & Menyusun Karung & 3 & Tindakan dalam waktu dekat \\
\hline 4 & $\begin{array}{l}\text { Menyortir Arang Tempurung } \\
\text { Kelapa }\end{array}$ & 1 & Aman \\
\hline 5 & $\begin{array}{l}\text { Proses Quality Control Bubuk } \\
\text { Arang }\end{array}$ & 1 & Aman \\
\hline 6 & Proses Menyekrup Bubuk Arang & 2 & $\begin{array}{l}\text { Diperlukan beberapa waktu ke } \\
\text { depan }\end{array}$ \\
\hline 7 & Proses Mengambil Ember & 2 & $\begin{array}{l}\text { Diperlukan beberapa waktu ke } \\
\text { depan }\end{array}$ \\
\hline 8 & Proses Mengangkat Ember & 1 & Aman \\
\hline 9 & $\begin{array}{l}\text { Proses Menuangkan Ember Bubuk } \\
\text { Arang }\end{array}$ & 3 & Tindakan dalam waktu dekat \\
\hline 10 & Proses Molding (Pencetakan) & 2 & $\begin{array}{l}\text { Diperlukan beberapa waktu ke } \\
\text { depan }\end{array}$ \\
\hline 11 & $\begin{array}{l}\text { Proses Pemotongan Bahan } \\
\text { Cetakan }\end{array}$ & 1 & Aman \\
\hline 12 & Proses Mengambil Hasil Cetakan & 1 & Aman \\
\hline 13 & $\begin{array}{l}\text { Proses Penyusunan Cetakan Briket } \\
\text { Arang }\end{array}$ & 2 & $\begin{array}{l}\text { Diperlukan beberapa waktu ke } \\
\text { depan }\end{array}$ \\
\hline 14 & Proses Mengambil Kayu & 1 & Aman \\
\hline 15 & Proses Membawa Kayu & 1 & Aman \\
\hline 16 & Proses Memasukkan Kayu & 1 & Aman \\
\hline 17 & Packing Plastik & 1 & Aman \\
\hline 18 & Packing Box Karton & 1 & Aman \\
\hline 19 & Packing Tali & 2 & $\begin{array}{l}\text { Diperlukan beberapa waktu ke } \\
\text { depan }\end{array}$ \\
\hline
\end{tabular}

(Sumber: Pengolahan dari Berbagai Sumber)

B. Penilaian Postur Kerja Dengan Metode Quick Exposure Checklist (QEC)

Analisis QEC pada pekerja departemen produksi di PT. Truva pasifik terdiri dari beberapa tahapan yang dilakukan yaitu mengumpulkan data-data kuesioner yang diisi oleh pengamat dan juga pekerja (operator) yang ada pada departemen produksi. Berikut lembar skor QEC tahapan mengambil karung dapat dilihat pada Gambar 4.3. 


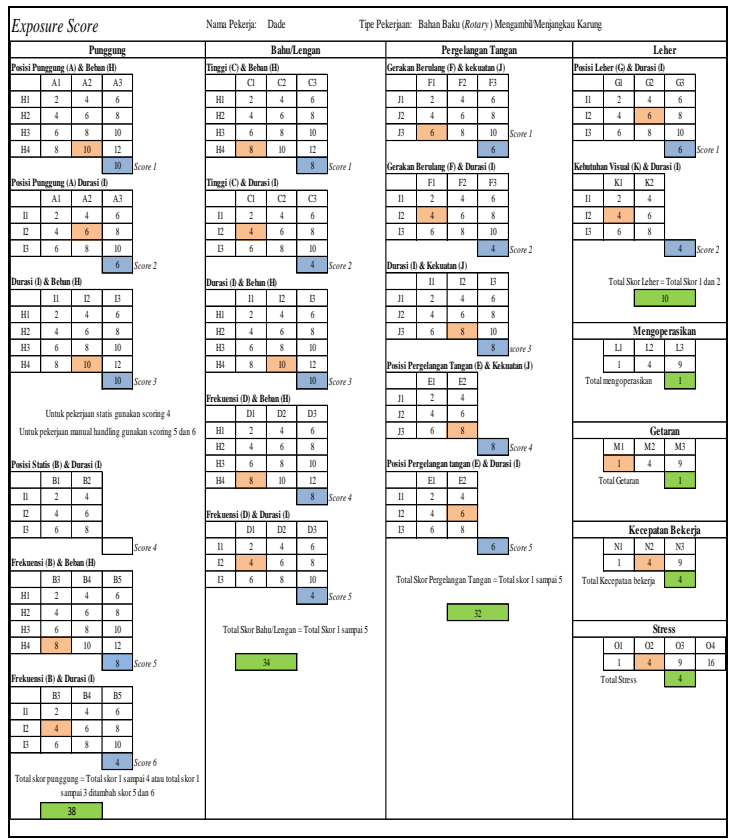

Gambar 4.3 Lembar Skor QEC Tahapan Mengambil Karung

(Sumber: Pengolahan dari Berbagai Sumber)

Berdasarkan Gambar 4.3 lembar skor QEC, berikut ini perhitungan pada tahapan mengambil karung:

Total skor QEC $=$ Skor (punggung (dinamis) + bahu/lengan + pergelangan + tangan + leher + mengoperasikan + getaran + kecepatan + bekerja + stress)

$$
\begin{aligned}
& =38+34+32+10+1+1+4+4 \\
& =124
\end{aligned}
$$

Untuk menentukan exposure level (E) maka dihitung dengan rumus sebagai berikut:

$$
\begin{aligned}
E(\%) & =\frac{X}{X \max } \times 100 \% \\
E(\%) & =\frac{124}{176} \times 100 \% \\
& =70,5 \%
\end{aligned}
$$

Pada pekerjaan stasiun kerja bahan baku (rotary) tahapan mengambil karung memiliki total skor QEC sebesar 124 yang termasuk dalam action level 4 dengan investigasi lebih lanjut dan dilakukan penanganan secepatnya dan nilai exposure level sebesar 70,5\% yang termasuk ke dalam high risk (risiko tinggi) bahaya terhadap sistem musculoskeletal disorders.

\section{Perbandingan Penilaian Risiko Ergonomi}

Berikut ini nilai akhir postur kerja pada 19 elemen kegiatan departemen produksi di PT. Truva Pasifik dari penilaian risiko ergonomi kedua metode OWAS dan QEC setelah

\begin{tabular}{|c|c|c|c|c|}
\hline $\begin{array}{l}\text { Tipe } \\
\text { Pekerjaan }\end{array}$ & $\begin{array}{c}\text { Nomor } \\
\text { Postur } \\
\text { Kerja }\end{array}$ & Elemen Kegiatan & $\begin{array}{c}\text { Nilai } \\
\text { Akhir } \\
\text { OWAS }\end{array}$ & $\begin{array}{l}\text { Nilai } \\
\text { Akhir } \\
\text { QEC }\end{array}$ \\
\hline \multirow{4}{*}{ Rotary } & 1 & $\begin{array}{l}\begin{array}{l}\text { Proses mengambil karung } \\
\text { (dinamis) }\end{array} \\
\end{array}$ & 4 & $70,5 \%$ \\
\hline & 2 & $\begin{array}{l}\begin{array}{l}\text { Proses mengangkat karung } \\
\text { (dinamis) }\end{array} \\
\end{array}$ & 3 & $65,9 \%$ \\
\hline & 3 & $\begin{array}{l}\text { Proses menyusun karung } \\
\text { (dinamis) }\end{array}$ & 3 & $63,6 \%$ \\
\hline & 4 & $\begin{array}{l}\text { Proses Menyortir arang } \\
\text { tempurung kelapa (statis) }\end{array}$ & 1 & $37,0 \%$ \\
\hline Diskmill & 5 & $\begin{array}{l}\text { Proses quality control bubuk } \\
\text { arang (statis) }\end{array}$ & 1 & $38,3 \%$ \\
\hline \multirow{4}{*}{ Mixer } & 6 & $\begin{array}{l}\text { Proses menyekrup bubuk arang } \\
\text { (dinamis) }\end{array}$ & 2 & $43,8 \%$ \\
\hline & 7 & $\begin{array}{l}\text { Proses mengambil ember } \\
\text { (dinamis) }\end{array}$ & 2 & $60,2 \%$ \\
\hline & 8 & $\begin{array}{l}\begin{array}{l}\text { Proses mengangkat ember } \\
\text { (dinamis) }\end{array} \\
\end{array}$ & 1 & $59,1 \%$ \\
\hline & 9 & $\begin{array}{l}\text { Proses menuangkan ember } \\
\text { bubuk arang (dinamis) }\end{array}$ & 3 & $63,1 \%$ \\
\hline Molding & 10 & Proses molding (statis) & 2 & $45,1 \%$ \\
\hline Cutting & 11 & $\begin{array}{l}\text { Proses pemotongan bahan } \\
\text { cetakan (statis) }\end{array}$ & 1 & $39,5 \%$ \\
\hline \multirow{2}{*}{ Susun (Sortir) } & 12 & $\begin{array}{l}\text { Mengambil hasil potongan } \\
\text { cetakan (dinamis) }\end{array}$ & 2 & $43,2 \%$ \\
\hline & 13 & $\begin{array}{l}\text { Proses penyusunan cetakan } \\
\text { briket arang (dinamis) }\end{array}$ & 2 & $47,7 \%$ \\
\hline \multirow{3}{*}{$\begin{array}{c}\text { Oven } \\
\text { (Pengeringan) }\end{array}$} & 14 & Mengambil kayu (dinamis) & 1 & $47,7 \%$ \\
\hline & 15 & Membawa kayu (dinamis) & 1 & $49,4 \%$ \\
\hline & 16 & Memasukkan kayu & 1 & $47,7 \%$ \\
\hline \multirow{3}{*}{$\begin{array}{c}\text { Packing } \\
\text { (Pengepakan) }\end{array}$} & 17 & Packing plastik (statis) & 1 & $39,5 \%$ \\
\hline & 18 & Packing box karton (statis) & 1 & $39,5 \%$ \\
\hline & 19 & Packing tali (dinamis) & 2 & $58,5 \%$ \\
\hline
\end{tabular}

dilakukan perhitungan dari kedua metode tersebut seperti pada Tabel 4.7.

Tabel 4.7 Nilai Akhir Postur Kerja OWAS dan QEC

(Sumber: Pengolahan dari Berbagai Sumber)

Tabel 4.10 Jumlah dan Persentase Postur Kerja Pada Metode OWAS dan QEC

\begin{tabular}{|c|c|c|c|c|}
\hline $\begin{array}{c}\text { Tingkat } \\
\text { Risiko }\end{array}$ & $\begin{array}{c}\text { Ovako Working } \\
\text { Posture Analysis } \\
\text { System (OWAS) }\end{array}$ & $(\%)$ & $\begin{array}{c}\text { Quick } \\
\text { Exposure } \\
\text { Checklist } \\
\text { (QEC) }\end{array}$ & $(\%)$ \\
\hline 1 & 10 & $53 \%$ & 5 & $26 \%$ \\
\hline 2 & 5 & $26 \%$ & 7 & $37 \%$ \\
\hline 3 & 3 & $16 \%$ & 6 & $32 \%$ \\
\hline 4 & 1 & $5 \%$ & 1 & $5 \%$ \\
\hline Total & 19 & $100 \%$ & 19 & $100 \%$ \\
\hline Stymber
\end{tabular}

(Sumber: Pengolahan dari Berbagai Sumber)

Hasil yang didapat pada Tabel $\mathbf{4 . 1 0}$ menunjukkan tingkat risiko tertinggi yang diperoleh dalam analisis menggunakan metode Quick Exposure Checklist (QEC) dengan tingkat risiko 2 (diperlukan beberapa waktu ke depan dan investigasi lebih lanjut) yaitu terdapat 7 postur kerja, sedangkan tingkat risiko 4 (kategori tindakan investigasi lebih lanjut dan dilakukan penanganan secepatnya) masingmasing diperoleh dari analisis menggunakan 
metode OWAS dan QEC yaitu 1 postur kerja pada tahapan mengambil karung stasiun kerja bagian rotary. Dari hasil perbandingan yang telah dijelaskan maka dapat ditarik kesimpulannya bahwa perbandingan antara metode OWAS dan QEC sama-sama dapat mengidentifikasi postur tubuh pekerja namun mempunyai kelebihan dan kekurangannya masing-masing terutama pada penelitian yang dilakukan peneliti terhadap postur kerja pada departemen produksi dimana elemen-elemen kegiatan postur kerja memiliki kegiatan yang berbeda-beda dengan gerakan dinamis dan statis tergantung dengan pekerjaan yang dikerjakan setiap elemen pekerjaan dibagian stasiun kerja masing-masing yang ada pada departemen produksi arang briket di PT. Truva Pasifik.

\section{Usulan Perbaikan}

Pekerjaan tahapan mengambil karung stasiun kerja rotary, tahapan mengangkat karung stasiun kerja rotary, tahapan menyusun karung stasiun kerja rotary, dan tahapan menuangkan ember bahan baku bubuk arang stasiun kerja mixer dengan metode OWAS dan QEC menghasilkan tingkat risiko yang tinggi serta kategori tindakan perbaikannya yaitu segera dilakukan tindakan. Usulan yang dilakukan adalah memperbaiki postur kerja yang mendapatkan tingkat risiko yang tinggi (berbahaya pada sistem musculoskeletal disorders). Berikut ini usulan perbaikan yang dilakukan pada postur kerja yang berisiko tinggi pada departemen produksi:

1. Usulan perbaikan postur kerja elemen kegiatan mengambil karung, elemen kegiatan mengangkat karung, dan elemen kegiatan menyusun karung pada stasiun kerja rotary departemen produksi dengan menambahkan alat bantu yang sesuai dengan risiko pekerjaan yang dilakukan pada stasiun kerja rotary agar dapat mengurangi risiko terjadinya musculoskeletal disorders (MSDs), alat bantu yang digunakan bisa berupa hand pallet atau trolley sebagai alat angkut barang yang digunakan dalam bekerja agar dapat lebih optimal dan meja atau tempat untuk meletakkan karung bahan baku agar tidak terlalu bawah.

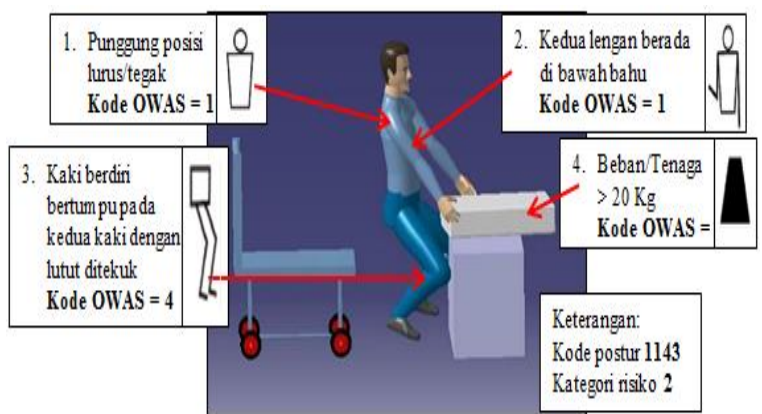

(Sumber: Jurnal Susilo, D.Y. dan Prastawa, H., 2017)

Gambar 4.4 Usulan Perbaikan Mengambil dan Mengangkat

Usulan perbaikan pada postur kerja menyusun karung dapat dilihat pada Gambar 4.5.

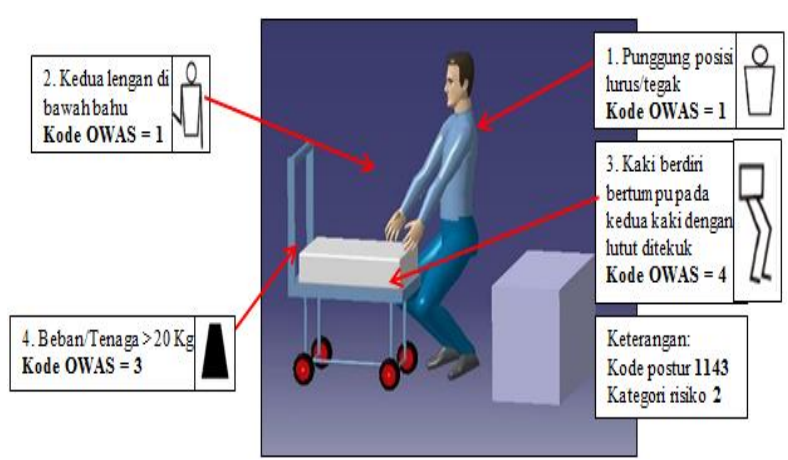

(Sumber: Jurnal Susilo, D.Y. dan Prastawa, H., 2017)

Gambar 4.5 Usulan Perbaikan Menyusun Barang

Skor OWAS dan QEC dari usulan perbaikan postur kerja pekerja pada bagian rotary elemen kegiatan mengambil karung, mengangkat dan menyusun karung departemen produksi di PT. Truva Pasifik maka didapatkan hasil yang bisa dilihat pada Tabel 4.11.

Tabel 4.11 Rekapitulasi Skor OWAS dan Skor QEC Usulan Perbaikan

\begin{tabular}{|c|c|c|l|l|}
\hline $\begin{array}{c}\text { Skor } \\
\text { OWAS }\end{array}$ & $\begin{array}{c}\text { Skor } \\
\text { QEC }\end{array}$ & $\begin{array}{c}\text { Level } \\
\text { Risik0 }\end{array}$ & \multicolumn{1}{|c|}{ Tindakan } & \multicolumn{1}{|c|}{ Postur Kerja } \\
\hline 2 & 2 & $\begin{array}{c}\text { Tindakan } \\
\text { korkifif }\end{array}$ & $\begin{array}{l}\text { Investivasi kbih lanjut ataul } \\
\text { perlu adanya perbaikan pada } \\
\text { waktu ke depan }\end{array}$ & $\begin{array}{l}\text { Usulan perbaikan postur kerja } \\
\text { mengambil, mengangkat dan } \\
\text { menyusun karung }\end{array}$ \\
\hline
\end{tabular}

(Sumber: Pengolahan dari Berbagai Sumber)

Berdasarkan Tabel 4.11 dapat dilihat postur kerja mengambil, mengangkat dan menyusun karung mendapatkan level risiko tindakan korektif dimana level risiko awal yang didapatkan dengan metode OWAS dan QEC 
sebelum usulan perbaikan yaitu dengan masingmasing mendapatkan level risiko 4 dan level risiko 3 , dengan adanya usulan perbaikan postur kerja pada operator elemen mengambil karung, mengangkat karung dan menyusun karung skor level risiko yang didapatkan yaitu skor 2 dimana skor level risiko ini bisa dilakukan tindakan korektif pada elemen kegiatannya dan hanya perlu perbaikan pada waktu ke depan. Nilai tingkat risiko dari high risk (risiko tinggi) ini turun setelah adanya usulan perbaikan gerakan postur kerja mengambil, mengangkat, menyusun karung dengan mengubah postur kerja dan menggunakan trolley dapat diaplikasikan pada pekerja stasiun kerja rotary.

2. Berikut ini usulan perbaikan pada postur kerja elemen menuangkan bubuk arang pada Gambar 4.6.

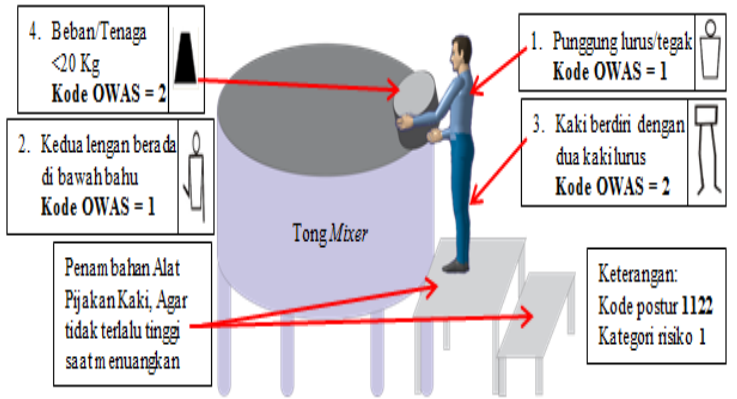

(Sumber: Pengolahan Data Peneliti)

Gambar 4.6 Usulan Perbaikan Postur Kerja Menuangkan Bubuk Arang

Kondisi usulan perbaikan postur kerja menuangkan bubuk arang Gambar 4.6:

a. Posisi punggung lurus;

b. Kedua lengan saat menuangkan barada di bawah bahu;

c. Kaki berdiri bertumpu pada kedua kaki lurus;

d. Berat beban yang diangkat $<20 \mathrm{Kg}$.

Kode OWAS pada postur kerja usulan adalah 1122 dengan kategori action code yang didapatkan yaitu tingkat risiko skor 1 (aman). Nilai tingkat risiko turun dari sebelum adanya usulan nilai tingkat risiko yang didapatkan yaitu skor OWAS dan QEC dengan kategori skor 3, sedangkan nilai skor usulan perbaikan yang didapatkan yaitu kategori skor 1 (aman) tidak ada bahaya pada sistem musculoskeletal. Usulan perbaikan dapat menambahkan alat bantu kerja dengan menambahkan trolley dan tempat dudukan pijakan kaki agar tidak terlalu tinggi saat menuangkan bubuk arang ke dalam tong mixer sehingga dapat mengurangi level risiko musculoskeletal yang terjadi. Kondisi usulan perbaikan postur kerja menuangkan bubuk arang bisa diaplikasikan pada elemen kegiatan menuangkan bubuk arang.

\section{KESIMPULAN}

Berdasarkan hasil penelitian analisa postur kerja pada operator departemen produksi di PT. Truva Pasifik, maka dapat diambil kesimpulan yaitu:

1. Postur kerja pada operator departemen produksi di PT. Truva Pasifik terdiri dari 19 elemen kegiatan, postur kerja tubuh operator yang paling dominan digunakan dan memiiki tingkat risiko musculoskeletal disorders paling tinggi meliputi pada bagian punggung (90,5\%) sebanyak 114 pekerja, diikuti bagian bahu kanan $(87,3 \%)$ sebanyak 110 pekerja, tangan kanan $(81,7 \%)$ sebanyak 103 pekerja, leher bagian bawah dan betis kanan $(78,6 \%)$ sebanyak 99 pekerja, serta pada bagian pinggang $(71,4 \%)$ sebanyak 90 pekerja.

2. Hasil aplikasi metode OWAS (Ovako Working Posture Analysis System) menunjukkan 4 postur kerja yang memerlukan perbaikan yaitu kategori skor 4 (perbaikan perlu dilakukan sekarang juga) terdapat pada elemen kegiatan mengambil karung, kategori skor 3 (perbaikan perlu dilakukan segera mungkin) terdapat pada kegiatan mengangkat karung, kegiatan menyusun karung, dan elemen kegiatan menuangkan ember bubuk arang, sedangkan hasil metode QEC menunjukkan nilai action level $(70,5 \%)$ pada kegiatan mengambil karung dengan tingkat risiko 4 (investigasi lebih lanjut dan dilakukan penanganan secepatnya), mengangkat karung action level (65,9\%), menyusun karung action level $(63,6 \%)$, dan proses menuangkan ember bubuk arang action level $(63,1 \%)$ mendapatkan tingkat risiko 3 (investigasi lebih lanjut dan dilakukan penanganan dalam waktu dekat).

\section{DAFTAR PUSTAKA}

Andriani, M. 2017. Identifikasi Postur Kerja Secara Ergonomi Untuk Menghindari Musculoskeletal Disorders. Jurnal Seminar Nasional Teknik Industri. Prodi Teknik Industri. Universitas Samudra. Aceh.

Ayodhya. 2015. Peran Ergonomi dalam Keselamatan Kerja. Jurnal Online. Fakultas Industri Kreatif. Universitas Telkom. Bandung. 
Beheshti, M., et al. (2015). Risk Assessment of Musculoskeletal Disorders by OVAKO Working posture Analysis System (OWAS) and Evaluate The Effect of Ergonomic Training on Posture of Farmers. Journal of Occupational Health and Epidemiology, 4(3), 130-138. Iran. https://doi.org/10.18869/acadpub.johe.4. $\underline{3.130 .}$.

Bernard, B. P., et al. 1997. Musculoskeletal Disorders and Workplace Factors, A Critical Review of Epidemiologic Evidence for Work-Related Musculoskeletal Disorders of the Neck, Upper Extremity, and Low Back. US Department of Health and Human Services. Public Health Service. Centers for Disease Control and Prevention: NIOSH. Publications Dissemination: Columbia Parkway Cincinnati.

Boshuizen, H., et al. 1993. Do Smokers Get More Back Pain. Amsterdam: The Netherlands: Elsevier.

Budhiman, A. M. 2015. Analisis Penilaian Tingkat Risiko Ergonomi Pada Pekerja Konstruksi Proyek Ruko Graha Depok Di Tahun 2015. Skripsi. Program Studi Kesehatan Masyarakat Fakultas Kedokteran dan Ilmu Kesehatan. Univeritas Islam Negeri (UIN) Syarif Hidayatullah. Jakarta.

Evelina, N. 2012. Analisis Tingkat Risiko Ergonomi Dan Keluhan Subjektif Musculoskeletal Disorders (MSDs) pada Pengrajin Sepatu Di Bengkel Sepatu Tata Kampung Ciomas Bogor Tahun 2012. Skripsi. Fakultas Kesehatan Masyarakat Departemen Kesehatan dan Keselamatan Kerja. Universitas Indonesia. Depok.

Grandjean, E. 1993 . Fitting The Task to The Man. 4th edt. Taylor \& Francis Inc. London.

Hasranti, Y. 2016. Hubungan Postur Kerja Dengan Keluhan Musculoskeletal Pada Pekerja Di PT. Maruki Internasional Indonesia Makassar. Program Studi
Fisoterapi Fakultas Kedokteran. Skripsi. Universitas Hasanudin. Makassar.

Hutabarat, Y. 2017. Dasar-Dasar Pengetahuan Ergonomi. Cetakan I. Penerbit: Media Nusa Creative. Malang.

Ilman, A., et al. 2013. Rancangan Perbaikan Sistem Kerja Dengan Metode Quick Exposure Check (QEC) Di Bengkel Sepatu X Di Cibaduyut. Jurnal Online Institut Teknologi Nasional Vol. 1, No.2. Bandung.

Irma, A. 2010. Usulan Perbaikan Postur Kerja Operator Dengan Menggunakan Metode Owas (Ovako Working Posture Analysis System) Di Terminal Kargo Polonia. Tugas Akhir. Program Pendidikan Sarjana Ekstensi Departemen Teknik Industri. Universitas Sumatera. Medan.

Karhu, O., Harkonen, R., Sorvali, P. and Vepsailanen, P. "Observing Working Posture in Industry: Example of OWAS Application". APPLIED ERGONOMICS 12 (1981). Page 13-17.

Krisdianto. 2015. Hubungan Faktor Individu Dan Faktor Pekerjaan Dengan Keluhan Musculoskeletal Akibat Kerja (Studi Pada Nelayan Di Desa Puger Wetan Kecamatan Puger Kabupaten Jember). Tugas Akhir. Program Kesehatan Lingkungan dan Kesehatan Keselamatan Kerja. Fakultas Kesehatan Masyarakat. Universitas Jember.

Madschen. 2012. Analisis Risiko Ergonomi dan Keluhan Musculoskeletal Disorders (MSDs) Pada Pekerja Tenun Elos Dikelurahan Martimbang dan kelurahan kebun Sayur Kotta pematang Siantar Tahun 2012. Thesis, Program Magister Keselamatan dan Kesehatan kerja Fakultas Kesehatan Masyarakat. Univesitas Indonesia. Depok.

Notoatmodjo, S. 2010. Metodologi Penelitian Kesehatan. Rineka Cipta: Jakarta.

Palit, H. C, dan Aysia, D. A. 2015. Analisis Postural Stress Operator Packing CV X. Jurnal. Proceeding Seminar Nasional dan 
Kongres PEI Teknik Industri Universitas Kristen Petra. Surabaya.

Prayuda, R. 2018. Analisis Tingkat Risiko Pada Pekerja Fabrikasi Dengan Metode Rapid Entire Body Assessment (REBA) dan Quick Exposure Checklist (QEC) Di PT. Techno Orbit Particle Filtration (TOP$F$ ). Tugas Akhir. Program Studi Teknik Industri. Fakultas Teknik Universitas Pamulang. Tangerang Selatan.

Pulat, B.M. 1992. Fundamentals of Industrials Ergonomics. Hall International. Englewood Cliffs. New Jersey. USA.

Rahmadhan, et al. 2017. Perbandingan Sensitivitas Metode REBA, OWAS, dan QEC Dalam Evaluasi Tingkat Risiko Postur Kerja (Studi Kasus di WL Alumunium Giwangan). Jurnal. Seminar Nasional Teknik Industri Universitas Gadjah Mada. Yogyakarta.

Rubiwanto, 2011. Penilaian Tingkat Risiko Ergonomi Pada Pekerjaan Mengangkat Dengan Niosh Lifting Equation Dipasar Induk Cipinang Tahun 2011. Skripsi. Fakultas Kesehatan Masyarakat Departemen Kesehatan dan Keselamatan Kerja. Universitas Indonesia. Depok.

Sastroasmoro, S. dan Ismail, S. 2011. DasarDasar Metodologi Penelitian Klinis. Banirupa Aksara: Jakarta.

Septiani, A. 2017. Faktor-Faktor Yang Berhubungan Dengan Keluhan Musculoskeletal Disorders (MSDs) Pada Pekerja Bagian Meat Preparation PT. Bumi Sarimas Indonesia Tahun 2017. Skripsi. Program Studi Kesehatan Masyarakat Fakultas Kedokteran Dan Ilmu Kesehatan. Univeritas Islam Negeri (UIN) Syarif Hidayatullah. Jakarta.

Sutalaksana, et al. 1979. Teknik Tata Cara Kerja. ITB: Bandung.

Tarwaka, et al. 2004. Ergonomi Untuk Keselamatan, Kesehatan dan Produktivitas Kerja. Penerbit: Uniba Press. Surakarta.

Tarwaka. 2010. Ergonomi Industri, DasarDasar Pengetahuan Ergonomi dan
Aplikasi Di Tempat Kerja. Penerbit: Harapan Press. Surakarta.

Tarwaka. 2015. Ergonomi Industri, DasarDasar Pengetahuan Ergonomi dan Aplikasi Di Tempat Kerja Ed. II dengan Revisi, Cetakan Ke-2. Penerbit: Harapan Press. Surakarta.

Tayyari, F., and J.L., Smith. 1997. Occupational Ergonomics Principles and Applications. T.J. Press Ltd, Great Britain.

Tobias Hellig, et al., 2018. The Interaction Effect of Working Postures on Muscle Activity and Subjectie Discomfort During Static Working Postures and its Correlation with OWAS. International Journal of Industrial Ergonomics 68(2018), 25-33. Achen University. Germany. https://doi.org/10.1016/j.ergon.2018.06. $\underline{006}$.

Utaminingsih, S., \& Candra, A. (2015). Penentuan Lama Waktu Istirahat Berdasarkan Beban Kerja Dengan Menggunakan Pendekatan Fisiologis Disaint JOHN'S SCHOOL BSD. Teknologi, Jurnal Ilmiah dan teknologi, Fakultas Teknik Dan Fakultas MIPA Universitas Pamulang, 11(29), 112.

https://bayu1194.wordpress.com/2014/04/03/m odul-5-ergonomi-dan-psk/, diakses pada tanggal 20 September 2018.

http://jodiwirlan.blogspot.com/2015/06/metode -penilaian-dalam-ergonomi.html copyright, diakses pada tanggal 20 September 2018. 